\title{
ECONOMIC AND ENVIRONMENTAL ASSESSMENT OF AN UNRELIABLE SUPPLY CHAIN MANAGEMENT
}

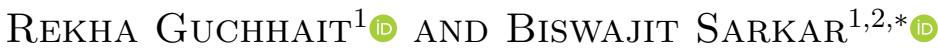

\begin{abstract}
The retailers within a supply chain management are the most important player as it has direct contact with the customers. Customers are the source of the money and information for the entire supply chain management. The equilibrium condition of the forward and backward supply chain is tight until it is reliable. But sometimes the retailers hide information from the manufacturer and this unreliability starts to propagate to the entire supply chain management. Blockchain technology is one of the secure decentralized systems to prevent unreliability. This study eliminates the unreliability of the system. A mathematical model is derived where the vendor-managed inventory policy is used by the single manufacturer to deal with multiple unreliable retailers. The entire process of manufacturing emits carbon. The carbon emission is controlled by the cap and trade policy and by paying the carbon tax. The results are found by the classical optimization technique and the numerical studies open up a way to the blockchain to deal with unreliable retailers. The decentralized system is a probable choice to prevent unreliability and thus the blockchain.
\end{abstract}

Mathematics Subject Classification. 90B06, 90C30.

Received November 13, 2020. Accepted August 14, 2021.

\section{INTRODUCTION}

The retail industry of any supply chain is very important as it has direct contact with the customers and the market demand. The information and money flow towards the upward supply chain management (SCM) through the retailers. Now, as the retailers are the end participant of the SCM, information asymmetry by the retailers within the SCM creates an unfaithful situation. It affects the inventory and ultimately affects the profit. The security of any type of information, nowadays, is controlled by a decentralized system. Blockchain technology is a decentralized system that secures information. It is a combination of several blocks which contain a certain limit of information. Once the information is stored in one block after decryption, that information cannot be encrypted again in a reverse way. Each block is connected with another block. Even if any retailer succeeds to change any information in one block, it will not affect other blocks. Whenever the manufacturer checks the entire system, it automatically appears that information in one block is changed and it differs from other blocks. Besides, the previous information already is in the system. If the information of all blocks can be

Keywords. Supply chain management, retail management, vendor managed inventory, cap and trade mechanism, logistics.

1 Department of Industrial Engineering, Yonsei University, 50 Yonsei-ro, Sinchon-dong, Seodaemun-gu, Seoul 03722, South Korea

2 Department of Computer Science and Engineering, Saveetha School of Engineering, Saveetha Institute of Medical and Technical Sciences, Saveetha University, 162, Poonamallee High Road, Velappanchavadi, Chennai, Tamil Nadu 600077, India

*Corresponding author: bsbiswajitsarkar@gmail.com 


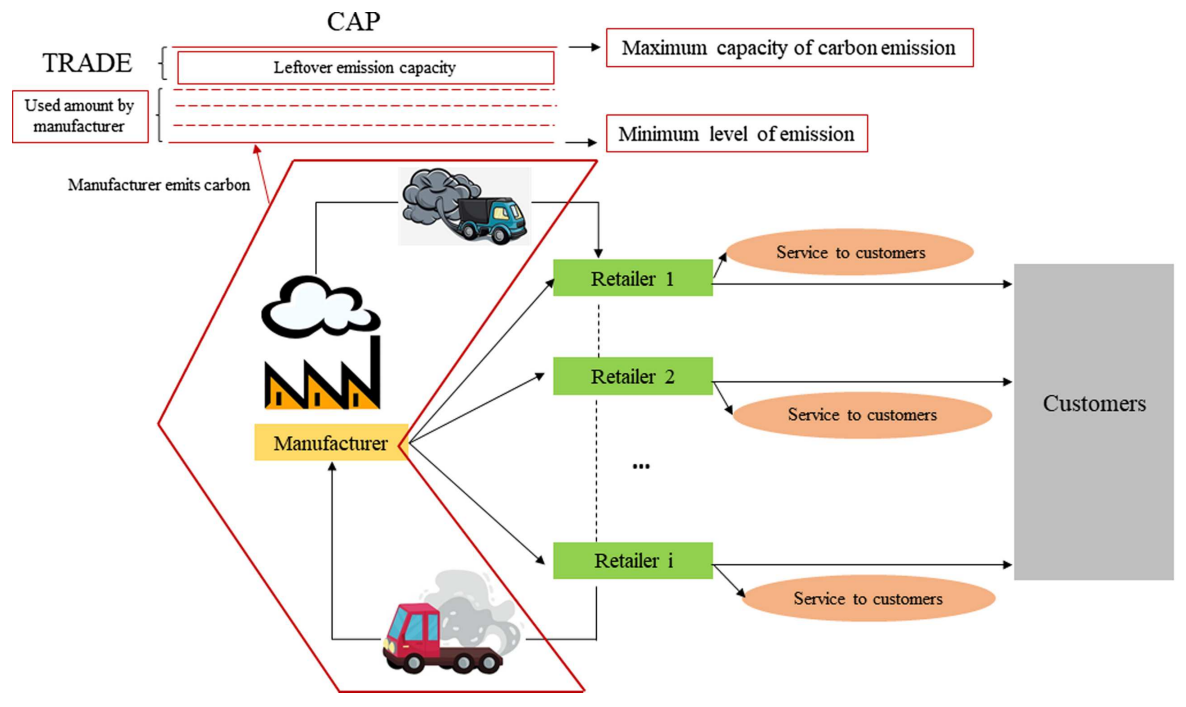

Figure 1. Framework of the study.

changed for changing information in one block, then only the entire system will change. But, this is next to impossible due to its decentralized nature and encryption policy.

The information asymmetry can be removed by blockchain technology. Besides, as retailers are unreliable in nature, the manufacturer uses vendor-managed inventory (VMI) policy for inventory control. The manufacturer retains the management of inventory through VMI. It gives the assurance to the manufacturer of not being cheated by the asymmetric information related to the inventory and the manufacturer can save the lost. VMI has an interesting feature of holding cost-sharing. This helps retailers to reduce their costs. Usually, the traditional policy gives more profit to retailers. Then the VMI policy fails to support the manufacturer viz., the manufacturer may not able to secure the inventory shrinkage. The revenue sharing policy ensures the profit of retailers in coordination policy. This makes the VMI policy effective.

The manufacturer collects the used items through backward logistics. Both forward and backward logistics are handled by the manufacturer. Distribution of the products to the retailers is managed by the forward logistics. The collection of used items are carried by the backward logistics process. The backward logistics depends upon the rate of collection of used products. It is not possible in reality that all the sold item can be collected, i.e., the collection rate will be $100 \%$. Besides, this collection depends upon distances. All processes of the system emit carbon into the environment. Industries, nowadays, are concerned about the environment along with the profit. The cap and trade (CAPT) policy has the maximum emission limit (cap) for an industry. If the emission exceeds the limit, the industry needs to buy an extra limit. If the industry has some remaining limit of emission after use, the excess emission limit can be sold to other industries. It is called "Trade". It helps to track the total emission. Figure 1 gives an outline of the study.

\section{Literature REVIEW}

A brief about the literature is given in this section.

\subsection{Supply chain management with strategies}

Different SCM issues are discussed by researchers from a different perspective. Different strategies are used within the SCM. A three-echelon SCM with an advanced payment system was discussed by Lashgari et al. [16]. 
Upstream- and downstream-payment policies were discussed by them. Whenever the SCM players are asymmetric in power, game strategies are used to decide the leader and follower of the SCM. A Stackelberg game policy was studied by Guchhait et al. [9] where the demand was advertisement-driven. Later, Sadjadi and Alirezaee [25] studied advertisement strategies for coordination-cooperative policies. Advertisement is always an interesting way to represent a product. But, still, there is uncertainty about the demand information, income, and environment also. Sarkar et al. [30], Zhang and Chu [40] discussed some uncertain situations about income and supply resources. Abdel-Aal and Selim [1] used robust optimization for uncertain demand. Rezaei et al. [23] discussed a robust supply chain where customer relationship was interpreted.

Sometimes it happens that the demand is a random variable that does not follow any known distribution function. That situation is handled by a distribution-free approach (DFA) which was invented by Scarf [31]. Later, that process was simplified by Gallego and Moon [7]. This process was used in several kinds of research (Moon et al. [18], Guchhait et al. [10]) to for the unknown random variable situation. Different inventory management systems are available for the proper management of inventory. VMI is one type of inventory management policy where the entire inventory of the system is managed by the manufacturer. Even the inventory is sent to the retailer, but it will be managed by the manufacturer (Taleizadeh et al. [35]). Bazan et al. [5] discussed the VMI and consignment stock (CS) for the restoration interruptions. Revenue sharing is another strategy of business that is used to maintain the ally within the SCM players. Heydari and Ghasemi [12] used the revenue sharing policy for the remanufacturing system under an uncertain environment. A revenue-sharing policy for a closed-loop supply chain (CLSC) was discussed by Rezayat et al. [24] to reduce waste management within the SCM.

\subsection{CAPT policy and carbon emission within the SCM}

Carbon emission is a very natural thing in any industry. Carbon can emit from almost all units of industry. The environmental issue one of the prime concerns of any industry. Several researches are going on in different aspects. Taleizadeh et al. [34] studied a CLSC where used products are collected. They used a price discount policy for the collection of the returned products. Another return policy for the used products is discussed by Taleizadeh et al. [33]. They used some policies to reduce carbon from the SCM. Sangal et al. [27] discussed the carbon emission from a defective production system. They considered that the cost for the emission is used within the system. Li et al. [17] investigated CAPT policy for vertical and horizontal cooperation. They found that asymmetric competition changes the bargaining power of an SCM. The CAPT policy for an online-to-offline (O2O) SCM was discussed by Ji et al. [13]. They compared the primary emission allowance with the CAPT capacity. Customers' low carbon preference was investigated by Ghosh et al. [8] for a dual-channel SCM.

\subsection{Unreliability and information flow within the retail management}

SCM is a collaboration of different players such as supplier, manufacturer, warehouse, and retailer. The number of players within an SCM is selected based on the size of the SCM. Now, it is not always possible that all players of an SCM will be loyal and reliable to each other. Some players may be unreliable and it starts to create problems for others, and finally for the entire system of the SCM. Information asymmetry between SCM players is one kind of unreliability. Information shortage, incomplete information, or hiding of information from one another are various kinds of unreliability issues. An asymmetric information flow was studied by Kegui et al. [15] for an enterprize. They discussed the carbon emission issue for the running strategies. Information asymmetry for a mixed SCM was discussed by Mukhopadhyay et al. [19]. An optimal design policy was established by Mukhopadhyay et al. [20] for the unreliability through information asymmetry within the SCM. Sardar et al. [28] used radio frequency identification (RFID) and machine learning to overcome the unreliability issue. RFID helps to prevent inventory misplacement. The unreliability within the SCM increases the chance of believing in other players. 
TABLE 1. Comparative study of existing literature.

\begin{tabular}{|c|c|c|c|c|c|}
\hline Author(s) & Model & Unreliability & $\begin{array}{c}\text { Contract } \\
\text { type }\end{array}$ & Emission & $\begin{array}{c}\text { Emission } \\
\text { control }\end{array}$ \\
\hline Sarkar et al. [29] & SCM & & VMI-CS & & \\
\hline Yu et al. [39] & $\mathrm{SCM}$ & & VMI & Carbon & carbon tax \\
\hline Kegui et al. [15] & Strategy & Information asymmetry & & Carbon & \\
\hline Ji et al. [13] & SCM & & & Carbon & CAPT \\
\hline Bai and Chen [4] & SCM & & & Carbon & CAPT \\
\hline Guchhait et al. [11] & SCM & Information asymmetry & VMI & & \\
\hline Ghosh et al. [8] & SCM & & buyback & Carbon & CAPT \\
\hline Mukhopadhay et al. [21] & $\mathrm{SCM}$ & Information asymmetry & & Carbon & \\
\hline Fan et al. [6] & Production-inventory & & & Carbon & Investment \\
\hline Karimian et al. [14] & Production & & VMI & & \\
\hline This study & $\mathrm{SCM}$ & Information asymmetry & VMI & Carbon & CAPT \& Carbon tax \\
\hline
\end{tabular}

\subsection{Virtues of blockchain for unreliability}

Removing or reducing unreliability within the SCM is challenging. Recent studies show that the decentralized system provides more security than the centralized system. On the edge of globalization, when every piece of information is shared through the Internet, the security of data is at high risk. Blockchain is one of the applications of the decentralized security policy. It secures data from tempered randomly. Yang et al. [38] discussed the blockchain technology for the steel and iron industries. They studied different layers of network and data in logistics. They developed a secure algorithm for that. The data transparency within a sustainable SCM in the context of the blockchain was discussed by Sunmola [32]. They figured out some architecture of a blockchain for the maximum visibility of information. A fuzzy Delphi method and Best-Worst Method (BWM) were used by Sahebi et al. [26] for humanitarian SCM to identify barriers to the use of blockchain technology in real-life problems. A survey on the textile industry was done by Agarwal et al. [2] to found out the usefulness of the blockchain for SCM traceability. Apart from information security only, blockchain technology is used in automated vehicles nowadays to secure safety. Ahamed and Karthikeyan [3] proposed a reinforcement learningbased heuristic method for automated vehicles that are used in SCM.

\subsection{Logistics support for the forward and reverse transportation}

Apart from the point of view of automated vehicles and traditional vehicles, transportation is one of the important units for SCM nowadays. Delivering products to retailers in time is very crucial for retailers. Forward logistics is always been a priority for the SCM players. Nowadays, reverse logistics gain attention due to environmental concerns. The collection of used products, defective products, end-of-life products, or waste products for proper disposal require transportation. Sometimes any SCM player takes responsibility for reverse logistics and sometimes third-party take responsibility for reverse logistics. This depends upon the SCM contract between different SCM players. Wijewickrama et al. [37] gave a review about the information-sharing mechanism for reverse logistics. They gave a perspective to improve information-sharing through reverse logistics. Noori-Daryan et al. [22] discussed different freight modes under incentive contracts. Ullah et al. [36] illustrated the use of third-party logistics for the collection of used products. They used reusable containers for transport which were returnable.

This study tries to remove the unreliability issue from the system. It is not always possible to expect all reliable players in the SCM. Thus, the security of information is one of the prime factors to remove the unreliability. The revenue sharing policy for the coordination case to make the SCM more reliable for the use of the VMI policy. The environmental aspect is considered by means of CAPT, carbon tax, and used product collection. The rest of the study is designed as follows: Section 3 states problem definition, notation, and assumptions about the study. Section 4 describes the mathematical modelling. Section 5 gives the solution methodology of 
the modelling. Section 6 provides the numerical example, case study and Section 7 provides the managerial implications of the model. Section 8 gives the conclusions of the research. Finally, some references are provided which are used in this study.

\section{Problem Definition, notation, and assumptions}

This section describes the proposed problem in brief. The related notation and hypotheses for the mathematical model are described in this section.

\subsection{Problem definition}

Unreliable multiple-retailers with a single-manufacturer formulates a two-echelon SCM for a single type of item. The retailers are independent of each other and an information asymmetry propagates through the SCM due to the hiding information from the manufacturer. To take care of the situation, the manufacturer uses the VMI policy for inventory control. In VMI policy, the manufacturer takes the control of the inventory handle from the retailers. A retailer orders items but the manufacturer decides how much to replenish and when. The manufacturer shares a percentage of revenue with retailers to ensure the profit of retailers in VMI policy. Besides this, the retailer is paying partial holding cost of the products. The entire system is under the CAPT policy and a carbon tax is paid by the manufacturer for the carbon emission from different activities. After the end of the forward SCM, the used products are collected from the retailers' location and send back to the manufacturer. The return rate of used items is $\varepsilon$.

\subsection{Notation}

The following notation is used to formulate the described model.

\begin{tabular}{cl}
\hline Index & retailer $k, k=1,2, \ldots, n$ \\
\hline$k$ & number of carbon emission sections, $l=1,2$ \\
& \\
Decision variables & service provided by the retailer $k$ to customers \\
$\gamma_{k}$ & lot size of retailer $k$ (units) \\
$\sigma_{k}$ & \\
Dependent variable & \\
$Q_{m}$ & lot size of the manufacturer (units), $Q_{m}=\sum_{k=1}^{n} \sigma_{k}$ \\
& \\
Parameters & demand of retailer $k$ (units) (random variable) \\
$\delta_{k}$ & mean value of demand $\delta_{k}, M=\sum_{k=1}^{n} M_{k}$ \\
$M_{k}$ & standard deviation of $\delta_{k}$ \\
$\Lambda_{k}$ & per unit selling price of retailer $k(\$ /$ unit) \\
$\rho_{k}$ & manufacturing cost per unit item $(\$ /$ unit) \\
$s$ & purchasing cost per unit item (wholesale cost) $(\$ /$ unit) \\
$v$ & goodwill lost cost of manufacturer $(\$ /$ unit/unit time) \\
$g$ & shortage cost of retailer $k$ per unit $(\$ /$ unit $/$ unit time) \\
$S_{r k}$ & retailer $k$ 's holding cost shared by the manufacturer $(\$ /$ unit/unit time) \\
$w_{r k}$ & service investment of retailer $k(\$)$ \\
$P_{k}$ & carbon emission from section $l$ \\
$e_{l}$ & carbon tax per unit product $(\$ /$ unit) \\
$t_{x}$ & carbon cap of the manufacturer (gallon) \\
$E_{c}$ &
\end{tabular}




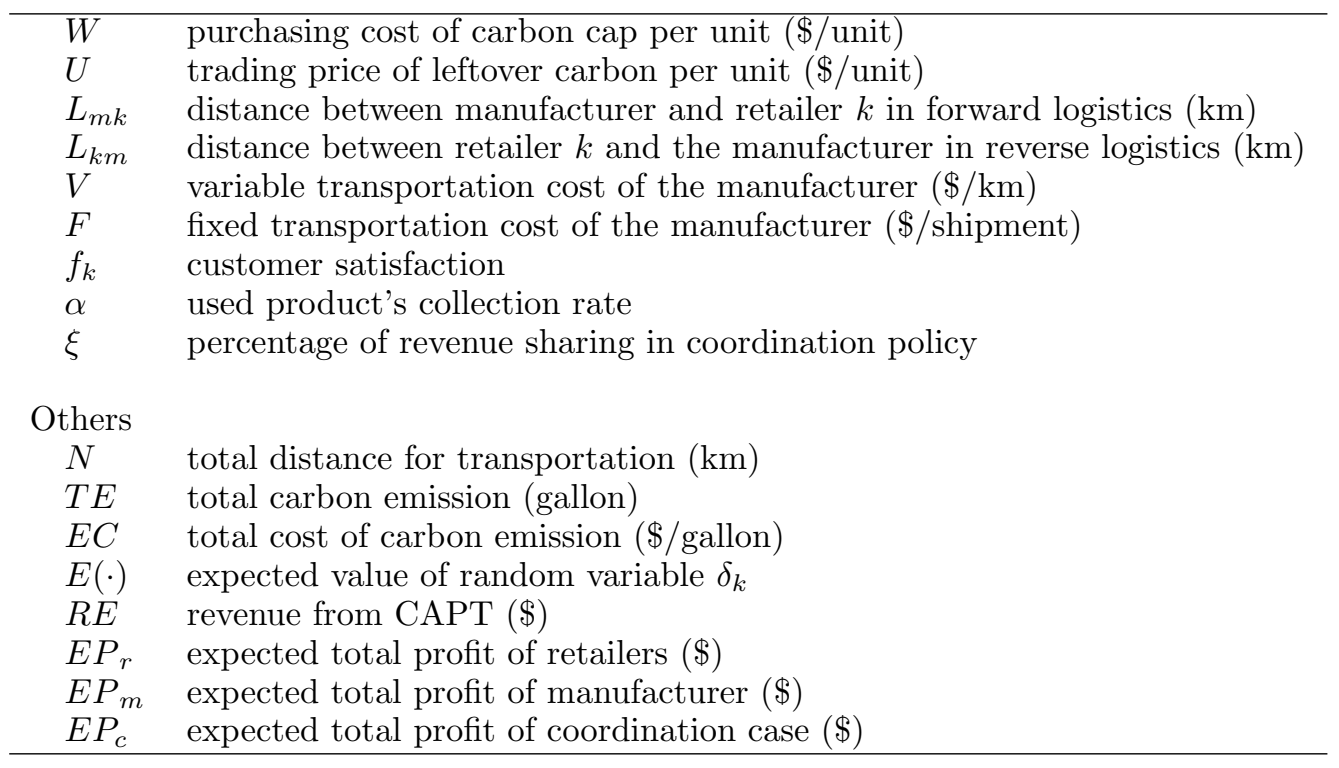

\subsection{Assumptions}

The following assumptions are used to develop the proposed study.

1. A single-manufacturer and multiple-retailers are involved in a two-echelon supply chain management. A single type of item is produced by the manufacturer and sent to multiple retailers. As the manufacturer is single, the wholesale price of item $v$ is the same for all retailers. As $n$ retailers are situated in different places, the selling price of a unit item is different.

2. The carbon is emitted from the entire system, viz., production, storage, and transportation. The manufacturer pays a carbon tax to the government for the carbon emission. Now, the carbon emission capacity of the manufacturer is limited by the CAPT policy. The maximum emission limit (cap) cannot be exceeded by the manufacturer. If there is any leftover limit of emission, the manufacturer sells the additional emission limit to another industry (trade).

3. Retailers are not fully reliable in the supply chain. They provide some service to their customers but the manufacturer is unaware of it. They hide this information from the manufacturer. As the manufacturer cannot trust these retailers, the manufacturer uses a VMI policy to control the inventory of retailers. It helps to prevent inventory shrinkage due to unreliability. The holding cost of retailers is shared by the manufacturer by the VMI contract.

4. Retailers can earn more profit in non-coordination policy than the coordination policy. To ensure the allegiance of retailers, the manufacturer uses a revenue-sharing policy with retailers for the coordination business. The manufacturer shares a percentage of the total profit with retailers.

5. Market demand of items is random and does not follow any known distribution function. Only the mean and the standard deviation are known.

6. The manufacturer delivers items to retailers through forward logistics. The used items from different retailers' positions are collected through reverse logistics. The reverse logistics cost of the manufacturer depends upon the collected used products.

\section{Mathematical modelling}

A two-echelon SCM is formulated with a single-manufacturer and multiple-retailers. The $n$ numbers of retailers are not interconnected with each other. Thus, there is no effect of retailer $k$ 's demand on retailer $k-1$. Retailer $k$ orders $\sigma_{k}$ quantity of items from the manufacturer. Then, the manufacturer receives total $Q_{m}=\sum_{k=1}^{n} \sigma_{k}$ 
order quantity from all retailers. Retailer $k$ has random market demand for a single type of items. The random variable associated with the market demand of retailer $k$ is $\delta_{k}$. Now, $\delta_{k}$ does not follow any known kind of probability distribution function. Only related mean $M_{k}$ and standard deviation $\Lambda_{k}$ are known. Then, to calculate the expected amount of shortage and excess items, the DFA is used (Moon et al. [18]). This approach gives a way to find out the maximum value of the expected shortage quantity. With the help of the lemma from Gallego and Moon [7], the expected shortage quantity of retailer $k$ is $E\left(\delta_{k}-\sigma_{k}\right)^{+} \leq \frac{1}{2}\left[\sqrt{\Lambda_{k}^{2}+\left(\sigma_{k}-M_{k}\right)^{2}}-\left(\sigma_{k}-M_{k}\right)\right]$, for any cumulative distribution function $\mathrm{F} \in \mathbf{F}$, the set of the cumulative distribution function. The expression $E\left(\delta_{k}-\sigma_{k}\right)^{+}$represents the positive value between $\left(\delta_{k}-\sigma_{k}\right)$ and zero.

\subsection{Manufacturer's model}

A single-manufacturer produces a single-type of items and sends those to the retailers. The total mean value of the demand is $M=\sum_{k=1}^{n} E\left(\delta_{k}\right)=\sum_{k=1}^{n} M_{k}$ and the ordered quantity of items is $Q_{m}=\sum_{k=1}^{n} \sigma_{k}$. The manufacturer receives orders and delivers products within a negligible lead time duration. The used products are collected by the manufacturer. The inventory management is taken care of by the manufacturer by using the VMI. The carbon emission from the manufacturing system is taken into consideration by the manufacturer. A CAPT policy is used to restrict the carbon emission in nature and a carbon tax is paid by the manufacturer for the emitted carbon. The associated costs and revenue are given below.

\subsubsection{Carbon tax for carbon emission}

All sectors emit carbon in nature, i.e., production unit, holding unit, and transportation unit. Energy is needed in every sector for workdone. Per unit emission from the manufacturing unit is $e_{1}$ and the transportation unit is $e_{2} . N$ is the total transportation distance for both forward and reverse logistics. Therefore, the above equation can be written as

$$
T E=e_{1} Q_{m}+e_{2} N
$$

The first term stands for the emission from the production unit and the second term represents the emission from the transportation unit. If $t_{x}$ is the per unit carbon tax, then the total carbon tax for the emission $T E$ is

$$
E C=t_{x}\left\{e_{1} Q_{m}+e_{2} N\right\}
$$

\subsubsection{CAPT policy for carbon emission}

The CAPT policy restricts unlimited carbon emissions from a manufacturing site. An industry buys some carbon cap $\left(E_{c}\right)$ from the government or associated agency at a price $W$. Then, that industry is eligible to emit carbon until the cap limit. In any case, if there is some extra unused emission limit, that limit is sold to another industry at price $U(W \geq U)$. In either case, if the emission limit $E_{c}$ is exhausted, then the industry will buy limit from outside. Then, associated expressions are as follows:

$$
E_{c}-T E=E_{c}-\left(e_{1} Q_{m}+e_{2} N\right), T E-E_{c}=\left(e_{1} Q_{m}+e_{2} N\right)-E_{c} .
$$

The first expression is the unused capacity of emission. The second expression is the shortage amount of emission limit when the manufacturer emits carbon more than the cap limit. Therefore, the revenue from the CAPT policy is $R E=U\left(E_{c}-T E\right)^{+}-W\left(T E-E_{c}\right)^{+}=U\left(E_{c}-T E\right)+(U-W)\left(T E-E_{c}\right)^{+}$. Using the maximum shortage quantity of carbon emission, the maximum revenue is

$$
R E \leq U\left(E_{c}-T E\right)+\frac{U-W}{2}\left(\sqrt{\left(T E-E_{c}\right)^{2}}+\left(T E-E_{c}\right)\right) .
$$




\subsubsection{Transportation cost}

The manufacturer sends items to retailers and collects used products. A fixed and variable type transportation cost is used for item transport. Every transport system has a base cost which is fixed. Here, it is considered as $F$. Whatever the distance and items, the minimum transportation cost will not be minimum from $F$. The variable transportation cost depends upon the ordered quantity and distance between the manufacturer and each retailer. For forward logistics, the distance between the manufacturer and retailer $k$ is $L_{m k}$. The transportation cost for forward logistics is $F+V \sum_{k=1}^{n} \sigma_{k} L_{m k}$. For reverse logistics, the distance between the retailer $k$ and the manufacturer is $L_{k m}$. The collection rate of used products is $\alpha$. Then the collected products for transportation is $\alpha \sum_{k=1}^{n} \sigma_{k}$. The transportation cost for reverse logistics is $F+V \alpha \sum_{k=1}^{n} \sigma_{k} L_{k m}$. Therefore, the total cost of transportation is $2 F+V\left(\sum_{k=1}^{n} \sigma_{k} L_{m k}+\alpha \sum_{k=1}^{n} \sigma_{k} L_{k m}\right)$.

\subsubsection{Manufacturing cost}

The manufacturer produces items as per the order quantity. Meanwhile, the manufacturer receives the order of total $Q_{m}$ quantity from $n$ retailers. If the unit manufacturing cost is $s$, then the manufacturing cost for $Q_{m}$ quantity of items is $s Q_{m}=s \sum_{k=1}^{n} \sigma_{k}$.

\subsubsection{Holding cost}

The manufacturer pays the holding cost of retailers. Now, as the market demand is random and does not fit in any known probability distribution function, there may be some extra items that are not sold by retailers. Those items require a holding cost. The expected surplus amount is $\frac{1}{2}\left[\sqrt{\Lambda_{k}^{2}+\left(\sigma_{k}-M_{k}\right)^{2}}+\left(\sigma_{k}-M_{k}\right)\right]$. If $w_{r_{k}}$ is the unit holding cost, then the total holding cost is $\sum_{k=1}^{n} \frac{w_{r_{k}}}{2}\left[\sqrt{\Lambda_{k}^{2}+\left(\sigma_{k}-M_{k}\right)^{2}}+\left(\sigma_{k}-M_{k}\right)\right]$.

\subsubsection{Goodwill lost cost}

Whenever the retailers face a shortage, the manufacturer faces the effect of that loss. It indirectly affects the goodwill of the manufacturer. The expected shortage quantity is $\frac{1}{2}\left[\sqrt{\Lambda_{k}{ }^{2}+\left(\sigma_{k}-M_{k}\right)^{2}}-\left(\sigma_{k}-M_{k}\right)\right]$. If the unit goodwill lost cost of the manufacturer is $g$, then the total goodwill lost cost is $g \sum_{k=1}^{n} \frac{1}{2}\left[\sqrt{\Lambda_{k}^{2}+\left(\sigma_{k}-M_{k}\right)^{2}}-\left(\sigma_{k}-M_{k}\right)\right]$.

\subsubsection{Wholesale price}

The manufacturer sells an item to retailers in a unit wholesale price $v$. This generates revenue for the manufacturer. The manufacturer receives order for $Q_{m}$ quantity of items from $n$ retailers. Therefore, the revenue of the manufacturer is $v Q_{m}$.

\subsubsection{Total profit of the manufacturer}

Thus, the expected total profit of the manufacturer is given by the following expression:

$$
\begin{aligned}
E P_{m}\left(\sigma_{k}\right) & =(v-s) Q_{m}-\sum_{k=1}^{n} \frac{w_{r k}}{2}\left[\sqrt{\Lambda_{k}^{2}+\left(\sigma_{k}-M_{k}\right)^{2}}+\left(\sigma_{k}-M_{k}\right)\right]-\frac{g}{2} \sum_{k=1}^{n}\left[\sqrt{\Lambda_{k}^{2}+\left(\sigma_{k}-M_{k}\right)^{2}}\right. \\
& \left.-\left(\sigma_{k}-M_{k}\right)\right]-t_{x}\left[e_{1} Q_{m}+e_{2} N\right]-2 F-V\left(\sum_{k=1}^{n} \sigma_{k} L_{m k}+\alpha \sum_{k=1}^{n} \sigma_{k} L_{k m}\right)+U\left(E_{c}-T E\right) \\
& +\frac{U-W}{2}\left(\sqrt{\left(T E-E_{c}\right)^{2}}+\left(T E-E_{c}\right)\right) .
\end{aligned}
$$




\subsection{Retailer's model}

Multiple retailers are involved within a two-echelon SCM with a single-manufacturer. Retailers are unreliable in nature. They are hiding information from the manufacturer. This creates an information asymmetry and it propagates within the system. Retailers provide service to customers and the manufacturer is unaware of this information.

\subsubsection{Service investment and customer satisfaction cost}

The provided service $\left(\gamma_{k}\right)$ to customers is given by the retailer $k$. For the service, the retailer $k$ invests some amount of money and $P_{k}$ is the investment parameter. Then, the total investment for the service is $\sum_{k=1}^{n} \frac{P_{k} \gamma_{k}^{2}}{2}$. Now, customer satisfaction is related to the service. The satisfaction rate is related to the service which they are receiving from retailers. If $f_{k}$ is the cost parameter related to customer satisfaction, then the customer satisfaction cost is $\sum_{k=1}^{n}\left(1-\gamma_{k}\right)^{2} f_{k}$. Then, the total cost related to the service is $\sum_{k=1}^{n} \frac{P_{k} \gamma_{k}^{2}}{2}+\left(1-\gamma_{k}\right)^{2} f_{k}$.

\subsubsection{Purchasing cost}

All retailers purchase items from the same manufacturer. Hence the purchasing of each retailer is the same. Again, the purchasing cost is the same as the wholesale price of the manufacturer. If the unit purchasing cost is $v$ and the ordering quantity is $\sigma_{k}$, the total purchasing cost is $\sum_{k=1}^{n} v \sigma_{k}$.

\subsubsection{Shortage cost}

Whenever the expected demand $M_{k}$ is more than the ordered quantity $\sigma_{k}$, then shortage of items arrives. It creates a backordered situation. Retailer $k$ faces some loss due to the expected shortage amount $\frac{1}{2}\left[\sqrt{\Lambda_{k}^{2}+\left(\sigma_{k}-M_{k}\right)^{2}}-\left(\sigma_{k}-M_{k}\right)\right]$. If the unit shortage cost is $S_{r_{k}}$, then the total shortage cost is $\sum_{k=1}^{n} \frac{S_{r_{k}}}{2}\left[\sqrt{\Lambda_{k}^{2}+\left(\sigma_{k}-M_{k}\right)^{2}}-\left(\sigma_{k}-M_{k}\right)\right]$.

\subsubsection{Selling price}

The selling price of items for different retailers is different as retailers are situated in different regions. That is why, even the purchasing cost of each retailer is the same, the revenue of each retailer will vary. $\rho_{k}$ is the unit selling price of an item. Based on the condition of the expected demand and ordered quantity, two scenarios appear. When the $M_{k} \leq \sigma_{k}$ then the selling price is $\rho_{k} M_{k}$ and when $\sigma_{k} \leq M_{k}$ then the selling price is $\rho_{k} \sigma_{k}$. The revenue of retailer $k$ is

$$
\left\{\begin{array}{cc}
\rho_{k} M_{k}, & \delta_{k} \leq \sigma_{k} \\
\rho_{k} \sigma_{k}, & \sigma_{k}<\delta_{k} .
\end{array}\right.
$$

Then, the total revenue of all retailers are $\sum_{k=1}^{n} \rho_{k} E \min \left(\delta_{k}, \sigma_{k}\right)$.

\subsubsection{Total profit of retailers}

Therefore, the expected total profit of all retailers is

$$
\begin{aligned}
E P_{r}\left(\sigma_{k}, \gamma_{k}\right)= & \sum_{k=1}^{n} \rho_{k} M_{k}-v \sum_{k=1}^{n} \sigma_{k}-\frac{1}{2} \sum_{k=1}^{n}\left(S_{r_{k}}+\rho_{k}\right)\left(\sqrt{\Lambda_{k}^{2}+\left(\sigma_{k}-M_{k}\right)^{2}}-\left(\sigma_{k}-M_{k}\right)\right)-\sum_{k=1}^{n} \frac{P_{k} \gamma_{k}^{2}}{2} \\
& -\sum_{k=1}^{n}\left(1-\gamma_{k}^{2}\right) f_{k} .
\end{aligned}
$$




\subsubsection{Expected total profit for the coordination policy}

Hence, the expected total profit $\left(E P_{c}\right)$ of the SCM is

$$
\begin{aligned}
E P_{c}\left(\sigma_{k}, \gamma_{k}\right)= & \sum_{k=1}^{n} \rho_{k} M_{k}-s Q_{m}-\frac{1}{2} \sum_{k=1}^{n} w_{r k}\left[\sqrt{\Lambda_{k}^{2}+\left(\sigma_{k}-M_{k}\right)^{2}}+\left(\sigma_{k}-M_{k}\right)\right]-\frac{1}{2} \sum_{k=1}^{n}\left(S_{r_{k}}+g+\rho_{k}\right) \\
& {\left[\sqrt{\Lambda_{k}^{2}+\left(\sigma_{k}-M_{k}\right)^{2}}-\left(\sigma_{k}-M_{k}\right)\right]-\sum_{k=1}^{n} \frac{P_{k} \gamma_{k}^{2}}{2}-\sum_{k=1}^{n}\left(1-\gamma_{k}\right)^{2} f_{k}-t_{x}\left(e_{1} Q_{m}+e_{2} N\right) } \\
& -2 F-V\left(\sum_{k=1}^{n} \sigma_{k} L_{m k}+\alpha \sum_{k=1}^{n} \sigma_{k} L_{k m}\right)+U\left(E_{c}-T E\right)+\frac{U-W}{2}\left(\sqrt{\left(T E-E_{c}\right)^{2}}\right. \\
& \left.+\left(T E-E_{c}\right)\right) .
\end{aligned}
$$

\subsubsection{Revenue sharing for coordination policy}

The manufacturer uses the revenue sharing strategy for the coordination policy. A percentage $\xi$ of the total SCM profit is shared with retailers. This strategy helps the SCM from a different perspective. If retailers join the traditional SCM instead of the VMI policy, they may earn more profit. Besides this, retailers are unreliable. Traditional SCM does not require many inventory management policies or any other security policy for any kind of unpleasant situation. These circumstances are helpful for retailers. Then they may not join the SCM which uses the VMI policy. In other words, the revenue sharing encourages other SCM players. Then, total shared revenue with retailers for revenue sharing mechanism is $T S=\xi E P_{c}$.

\section{Solution methodology}

The mathematical model is solved by using the classical optimization technique. Optimum values are found by the first order derivatives and the globality of the optimum solutions are proved by the Hessian matrix. All the retailers and the manufacturer are of equal power in SCM. Thus, they maximize their own profit for the non-coordination case instead of the game policy. Both coordination and non-coordination cases are solved. Lemmas and propositions are proved to establish the optimum solutions.

\subsection{Non-coordination case}

Profits of the manufacturer and retailers are found separately. The manufacturer maximizes its own profit whereas retailers maximize its own profits.

\subsubsection{Manufacturer's case}

The manufacturer optimizes the value of $\sigma_{k}$. The optimum value is found by the first order derivative.

$$
\begin{aligned}
\frac{\partial E P_{m}}{\partial \sigma_{k}}= & v-s-\frac{\sigma_{k}-M_{k}}{2 \sqrt{\Lambda_{k}^{2}+\left(M_{k}-\sigma_{k}\right)^{2}}}\left(w_{r k}+g\right)-\frac{1}{2}\left(w_{r k}-g\right)-e_{1}\left(t_{x}+W\right)-V\left(L_{m k}+\alpha L_{k m}\right)=0 \\
\text { i.e., } \sigma_{k}^{*}= & M_{k}+\frac{\Lambda_{k} \Delta_{1}}{\sqrt{1-\Delta_{1}^{2}}}, \text { where } \Delta_{1}=\frac{\Upsilon}{w_{r k}+g}, \Upsilon=2\left(v-s-\left(t_{x}+W\right) e_{1}-V\left(L_{m k}+\alpha L_{k m}\right)\right) \\
& -w_{r k}+g .
\end{aligned}
$$

The above Equation (5.1) provides the optimum value if the following Lemma 1 holds.

Lemma 5.1. Equation (5.1) gives the optimal value of the ordered quantity $\sigma_{k}$ if $\Delta_{1}^{2}<1$. 
Proposition 5.1. From the condition of the classical optimization, the objective function $E P_{m}$ is global maximum if $\frac{\partial^{2} E P_{m}}{\partial \sigma_{k}^{2}}<0$.

Proof. The second order derivative of the objective function $E P_{m}$ with respect to $\sigma_{k}^{*}$ is

$$
\frac{\partial^{2} E P_{m}}{\partial \sigma_{k}^{2}}=-\frac{1}{2} \frac{\left(w_{r k}+g\right) \Lambda_{k}^{2}}{\left(\Lambda_{k}^{2}+\left(M_{k}-\sigma_{k}\right)^{2}\right)^{\frac{3}{2}}}
$$

which is clearly $<0$ as $\left(w_{r k}+g\right) \Lambda_{k}^{2}>0$ and $2\left(\Lambda_{k}^{2}+\left(M_{k}-\sigma_{k}\right)^{2}\right)^{\frac{3}{2}}>0$. Thus, the objective function attains a global maximum value. Hence the proof.

\subsubsection{Retailer's case}

The objective function of all retailers is given by Equation (4.6). The retailer's decision variables are ordered quantity $\left(\sigma_{k}\right)$ and service $\gamma_{k}$. The first order derivatives and the corresponding values are

$$
\begin{gathered}
\frac{\partial E P_{r}}{\partial \sigma_{k}}=-v-\frac{S_{r_{k}}+\rho_{k}}{2}\left[\frac{\sigma_{k}-M_{k}}{\sqrt{\Lambda_{k}^{2}+\left(\sigma_{k}-M_{k}\right)^{2}}}-1\right]=0 \\
\text { i.e., } \sigma_{k}^{*}=M_{k}+\frac{\Lambda_{k} \Delta_{2}}{\sqrt{1-\Delta_{2}^{2}}} \text { where } \Delta_{2}=\frac{-2 v+S_{r_{k}}+\rho_{k}}{\rho_{k}+S_{r_{k}}}, \\
\frac{\partial E T P_{r}}{\partial \gamma_{k}}=-P_{k} \gamma_{k}+2 f_{k}\left(1-\gamma_{k}\right)=0, i . e ., \gamma_{k}^{*}=\frac{2 f_{k}}{P_{k}+2 f_{k}} .
\end{gathered}
$$

These give the value of the ordered quantity and service.

Lemma 5.2. The value of the ordered quantity $\sigma_{k}$ of Equation (5.2) is optimal if $\Delta_{2}^{2}<1$.

Proposition 5.2. The value of the objective function $E P_{r}$ for the values of $\sigma_{k}^{*}$ and $\gamma_{k}^{*}$ of Equation (5.2) is global maximum if the principal minors of the Hessian matrix are alternating in sign at $\left(\sigma_{k}^{*}, \gamma_{k}^{*}\right)$.

Proof. The second order derivatives of the objective function $E P_{r}$ with respect to $\sigma_{k}$ and $\gamma_{k}$ are

$$
\frac{\partial^{2} E P_{r}}{\partial \sigma_{k}^{2}}=-\frac{\left(S_{r_{k}}+\rho_{k}\right) \Lambda_{k}^{2}}{2\left(\Lambda_{k}^{2}+\left(M_{k}-\sigma_{k}\right)^{2}\right)^{\frac{3}{2}}}<0, \frac{\partial^{2} E P_{r}}{\partial \gamma_{k}^{2}}=-\left(P_{k}+2 f_{k}\right)<0
$$

as all the expressions $\left(S_{r_{k}}+\rho_{k}\right) \Lambda_{k}^{2}, 2\left(\Lambda_{k}^{2}+\left(M_{k}-\sigma_{k}\right)^{2}\right)^{\frac{3}{2}}$, and $P_{k}+2 f_{k}$ are positive. Hence, first principal minors are less than zero. Again,

$$
\frac{\partial^{2} E P_{r}}{\partial \sigma_{k} \partial \gamma_{k}}=0=\frac{\partial^{2} E P_{r}}{\partial \gamma_{k} \partial d}
$$

The second order principal minor of the retailer $k$ is

$$
\left|H_{22 k}\right|=\left|\begin{array}{cc}
\frac{\partial^{2} E P_{r}}{\partial \sigma_{k}^{2}} & \frac{\partial E P_{r}}{\partial \sigma_{k} \partial \gamma_{k}} \\
\frac{\partial^{2} E P_{r}}{\partial \gamma_{k} \partial \sigma_{k}} & \frac{\partial^{2} E P_{r}}{\partial \gamma_{k}^{2}}
\end{array}\right|=\frac{\left(S_{r_{k}}+\rho_{k}\right) \Lambda_{k}^{2}}{2\left(\Lambda_{k}^{2}+\left(M_{k}-\sigma_{k}\right)^{2}\right)^{\frac{3}{2}}}\left(P_{k}+2 f_{k}\right)>0 .
$$

All the expressions are positive. Thus, the determinant value is positive. As the principal minors are alternating in sign, this proves that the required results are global maximum for retailer $k$. Hence the proof. 


\subsection{Coordination case}

The first order derivatives of the $\operatorname{ETP}\left(\sigma_{k}, \gamma_{k}\right)$ with respect to the decision variables $\sigma_{k}, \gamma_{k}$ gives the values of the decision variables.

$$
\begin{aligned}
\frac{\partial T P_{c}}{\partial \sigma_{k}}= & 0, \text { i.e., } \sigma_{k}^{*}=M_{k}+\frac{\Lambda_{k} \Delta_{3}}{\sqrt{1-\Delta_{3}^{2}}} \text { where } \Delta_{3}=\frac{\Gamma}{w_{r k}+\rho_{k}+S_{r_{k}}+g}, \Gamma=2\left(-s-\left(t_{x}+W\right) e_{1}\right. \\
& \left.-V\left(L_{m k}+\alpha L_{k m}\right)\right)-w_{r k}+\rho_{k}+S_{r_{k}}+g, \\
\frac{\partial E P_{c}}{\partial \gamma_{k}}= & 0 \text { i.e., } \gamma_{k}^{*}=\frac{2 f_{k}}{P_{k}+2 f_{k}} .
\end{aligned}
$$

Equation (5.3) gives the optimum values of the decision variables as $\sigma_{k}^{*}$ and $\gamma_{k}^{*}$. The sufficient condition of the classical optimization gives the global optimality of the solutions.

Lemma 5.3. The optimal value of $\sigma_{k}^{*}$ exists if $\Delta_{3}^{2}<1$.

Proposition 5.3. The objective function $E P_{c}$ has the global maximum at the optimal values $\sigma_{k}^{*}$ and $\gamma_{k}{ }^{*}$ if the principal minors are alternating in signs.

Proof. The second order derivative of $E P_{c}$ with respect to the decision variables are

$$
\frac{\partial^{2} T P_{c}}{\partial \sigma_{k}^{2}}=-\frac{1}{2} \frac{\left(w_{r k}+\rho_{k}+S_{r_{k}}+g\right) \Lambda_{k}{ }^{2}}{\left(\Lambda_{k}^{2}+\left(M_{k}-\sigma_{k}\right)^{2}\right)^{\frac{3}{2}}}<0,
$$

as values of the expressions $\left(w_{r k}+\rho_{k}+S_{r_{k}}+g\right) \Lambda_{k}^{2}$ and $2\left(\Lambda_{k}^{2}+\left(M_{k}-\sigma_{k}\right)^{2}\right)^{\frac{3}{2}}$ are positive.

$$
\begin{aligned}
\frac{\partial^{2} T P_{c}}{\partial \gamma_{k}^{2}} & =-P_{k}^{2}-2 f_{k}<0, \text { as } P_{k}^{2}+2 f_{k}>0, \\
\frac{\partial^{2} T P_{c}}{\partial \sigma_{k} \partial \gamma_{k}} & =0=\frac{\partial^{2} E P_{c}}{\partial \gamma_{k} \partial \sigma_{k}} .
\end{aligned}
$$

Thus, the first order principal minor is negative. Now, the second order principal minor is

$$
\begin{aligned}
\left|H_{22 k}\right| & =\left|\begin{array}{ll}
\frac{\partial^{2} T P_{c}}{\partial \sigma_{k}^{2}} & \frac{\partial^{2} T P_{c}}{\partial \sigma_{k} \partial \gamma_{k}} \\
\frac{\partial^{2} T P_{c}}{\partial \gamma_{k} \partial \sigma_{k}} & \frac{\partial^{2} T P_{c}}{\partial \gamma_{k}^{2}}
\end{array}\right| \\
\text { i.e., }\left|H_{22 k}\right| & =\frac{1}{2} \frac{\left(w_{r k}+S_{r_{k}}+\rho_{k}+g\right) \Lambda_{k}^{2}}{\left(\Lambda_{k}^{2}+\left(M_{k}-\sigma_{k}\right)^{2}\right)^{\frac{3}{2}}}\left[P_{k}^{2}+2 f_{k}\right]>0 .
\end{aligned}
$$

All the expressions are positive in nature. Hence, the value of the second principal minor is greater than zero and it is positive is a sign. Therefore, all principal minors are alternating in sign. Therefore, the objective function $E P_{c}$ attains its global maximum at $\sigma_{k}^{*}$ and $\gamma_{k}^{*}$.

\section{NUMERICAL EXPERIMENTS}

A numerical example is given to validate the theoretical model. Two examples are provided. Four retailers are used to justify the multiple-retailers. Input values are taken from Bai and Chen [4] and Sarkar et al. [29]. 
TABLE 2. Input values of parameters.

\begin{tabular}{llll}
\hline Parameters & Values & Parameters & Values \\
\hline$n$ & 4 & $\left(S_{r 1}, S_{r 2}, S_{r 3}, S_{r 4}\right)$ & $\$(8,7,9,7) /$ unit \\
$\left(\rho_{1}, \rho_{2}, \rho_{3}, \rho_{4}\right)$ & $\$(200,205,208,206) /$ unit & $\left(\Lambda_{1}, \Lambda_{2}, \Lambda_{3}, \Lambda_{4}\right)$ & $(6.3,6.6,6.8,6.2)$ \\
$\left(M_{1}, M_{2}, M_{3}, M_{4}\right)$ & $(400,428,340,380)$ unit & $\left(P_{1}, P_{2}, P_{3}, P_{4}\right)$ & $\$(2,3,5,4)$ \\
$\left(w_{r 1}, w_{r 2}, w_{r 3}, w_{r 4}\right)$ & $\$(0.51 \mathrm{~s}, 0.55 \mathrm{~s}, 0.52 \mathrm{~s}, 0.51 \mathrm{~s}) /$ unit/year & $\left(f_{1}, f_{2}, f_{3}, f_{4}\right)$ & $(0.71,0.78,0.43,0.65)$ \\
$\left(L_{1 m}, L_{2 m}, L_{3 m}, L_{4 m}\right)$ & $(43,42,45,43) \mathrm{km}$ & $\left(L_{m 1}, L_{m 2}, L_{m 3}, L_{m 4}\right)$ & $(45,46,45,45) \mathrm{km}$ \\
$g$ & $\$ 23 /$ unit & $(s, v)$ & $\$(80,160) /$ unit \\
$\alpha$ & 0.5 & $V$ & $\$ 0.13 / \mathrm{km}$ \\
$F$ & $\$ 0.5 /$ shipment & $(U, W)$ & $\$(2.1,3.1) /$ unit emission \\
$E_{c}$ & 6,000 gallon & $t_{x}$ & $\$ 3.1 /$ unit \\
\hline
\end{tabular}

TABLE 3. Optimum results of the model.

\begin{tabular}{llll}
\hline Coordination case & & & \\
\hline Variables & Optimum values & Results & Total profit \\
\hline $\begin{array}{l}\left(\sigma_{1}{ }^{*}, \sigma_{2}{ }^{*}, \sigma_{3}{ }^{*}, \sigma_{4}{ }^{*}\right) \\
\left(\gamma_{1}{ }^{*}, \gamma_{2}{ }^{*}, \gamma_{3}{ }^{*}, \gamma_{4}{ }^{*}\right)\end{array}$ & $\begin{array}{l}(398.61,426.59,338.74,378.78) \text { unit } \\
(0.42,0.34,0.15,0.25)\end{array}$ & $E P_{c}$ & $\$ 168,806.93$ \\
\hline $\begin{array}{l}\text { Non-coordination case } \\
\text { Manufacturer }\end{array}$ & $1,583.41$ unit & $E P_{m}$ & $\$ 103,229.40$ \\
$\begin{array}{l}Q_{m} \\
\text { Retailer } \\
\left(\sigma_{1}{ }^{*}, \sigma_{2}{ }^{*}, \sigma_{3}{ }^{*}, \sigma_{4}{ }^{*}\right)\end{array}$ & $(395.97,424.09,336.33,376.40)$ unit & $E P_{r}$ & $\$ 66,683.77$ \\
$\left(\gamma_{1}, \gamma_{2}, \gamma_{3}, \gamma_{4}\right)$ & $(0.42,0.34,0.15,0.25)$ & & \\
\hline
\end{tabular}

\subsection{Example 1}

Input for Example 1 is given in Table 2.

The outputs of the Example 1 are given in Table 3.

Some data are changed from the literature due to the convergence of the numerical program. The expected total profit of the manufacturer is $\$ 103,229.40$ and the retailers' expected total profit is $\$ 66,683.77$. The total profit of the SCM in the coordination case is $\$ 168,806.93$. It is seen that $E P_{r}+E P_{m}>E P_{c}$ i.e., the profit in the non-coordination case is more than the profit in the coordination case. This is a characteristic of a blockchain. Thus, it is concluded from the numerical results that the system supports the non-coordination policy to deal with the unreliability.

\subsection{Revenue sharing in coordination case}

If the manufacturer shares more than $40 \%$ of the total profit with retailers, then the total profit of retailers will be more in the coordination case. Thus, the percentage of revenue sharing is $\xi=41 \%$ of the total SCM profit with retailers. The total SCM profit is $\$ 168,806.93$. Then, the sharing profit with retailers is $\xi E P_{c}=\$ 69,210.84$. The manufacturer has $\$ 99,596.09$ amount of profit from the SCM.

\subsection{Analysis of carbon emission}

Total 3, 874.28 gallon carbon is emitted from the SCM for the coordination case. From this, $71.67 \%$ emission is from the production sector and $28.33 \%$ is from the transportation sector. It is seen that the production unit emits more carbon than the transportation unit. The total emission from the non-coordination case is 3,947.53 gallons. Emission from transportation is $27.8 \%$ and from the production unit is $72.2 \%$. The coordination case emits less carbon in nature than the non-coordination case. In both cases, the production unit emits more carbon followed by the transportation unit. In Example 1, the emission cap $\left(E_{c}\right)$ was 6,000 gallon and the total 
TABle 4. Parameters for Example 2.

\begin{tabular}{llll}
\hline Parameters & Values & Parameters & Values \\
\hline$\left(\rho_{1}, \rho_{2}, \rho_{3}, \rho_{4}\right)$ & $\$(210,215,208,216) /$ unit & $\left(w_{r_{1}}, w_{r_{2}}, w_{r_{3}}, w_{r_{4}}\right)$ & $\$(0.45 \mathrm{~s}, 0.43 \mathrm{~s}, 0.45 \mathrm{~s}, 0.43 \mathrm{~s}) /$ unit $/$ year \\
$(v, s)$ & $\$(150,90) /$ unit & $E_{c}$ & 3,650 gallon \\
$a$ & $\$ 49 /$ unit & $F$ & $\$ 0.5 /$ shipment \\
$\left(L_{1 m}, L_{2 m}, L_{3 m}, L_{4 m}\right)$ & $(46,46,45,43) \mathrm{km}$ & $\left(L_{m 1}, L_{m 2}, L_{m 3}, L_{m 4}\right)$ & $(47,45,45,44) \mathrm{km}$ \\
\hline
\end{tabular}

emission $T E$ is less than $E_{c}$, in both cases. Thus, the excess amount is used for trading which contributes in generating revenue.

\subsection{Example 2}

The changed data for this example is listed in Table 4. Some data is the same as the example.

The case study has a similar result pattern as the example. In a non-coordination case, the manufacturer's profit is $\$ 66,111.90$ and the total profit of retailers is $\$ 93,965.57$. The total profit, in this case, is more than the profit of the coordination case. The profit of the SCM in the coordination case is $\$ 158,961.10$. Thus, results support the non-coordination policy for the elimination of the unreliability from the system. For the revenue sharing policy of the coordination case, if the manufacturer shares more than $59 \%$ of the total profit with retailers, then the profit of retailers in coordination case will be more. Hence, the percentage is $61 \%$ i.e., $\xi 158,961.10=\$ 96,966.27$ profit is shared with retailers.

The total emission in the coordination case is 3,905.48 gallons. The emission from the production unit is $71.35 \%$ and from the transportation unit is $28.65 \%$. For the non-coordination case, the total emission is $4,006.00$ gallons. The emission percentage from production is $72.06 \%$ whereas from transportation is $27.94 \%$. Emission from the non-coordination case is more than the emission from the coordination case. The Carbon emission cap $\left(E_{c}\right)$ in Example 2 was 3,650 gallon. Total emission $T E$ is more than $E_{c}$ in either case. Hence, the manufacturer buys the extra cap.

\subsection{Sensitivity analysis}

The sensitivity analysis represents the sensitiveness of the key parameters for the total profit of the SCM. The analysis is studied for the manufacturer and retailer 1 for the coordination case of Example 1. Figure 2 and Table 5 give changes and their representation.

- Manufacturing cost is the most affected cost within a range of $-50 \%$ to $+50 \%$. For $50 \%$ reduction of the manufacturing cost causes $+36.29 \%$ more profit and the profit increases $18.12 \%$ for $25 \%$ decrements of the manufacturing cost. The positive and negative changes are similar.

- The selling price is the second most affected parameter with a wide range. The positive and negative changes are almost similar. Whenever the selling price increases $50 \%$, then the profit increases $17.86 \%$ whereas the profit decreases $15.02 \%$ when the selling price decreases $50 \%$, the profit increases $23.53 \%$. Increment of the selling price of an item is profitable for both the manufacturer and retailers. At a glance, the profit decreasing rate is a little less than the profit increasing rate.

- The variable transportation cost is more sensitive than the fixed transportation cost. The fixed transportation cost has almost no changes from $-50 \%$ to $+50 \%$ and the changes are small. The total profit increases $3.97 \%$ for $50 \%$ decrements of the variable transportation cost. As variable cost is dependent upon the ordered quantity and collection of returned products, the manager should take care of the variable transportation cost.

- If the carbon tax rate decreases $50 \%$, then the profit increases $3.53 \%$ and vice verse. Positive and negative percentage changes are similar. The purchasing price of the carbon cap is the next most sensitive parameter among all. Both cap purchasing price and trading price are directly proportional to the profit. Whenever the 


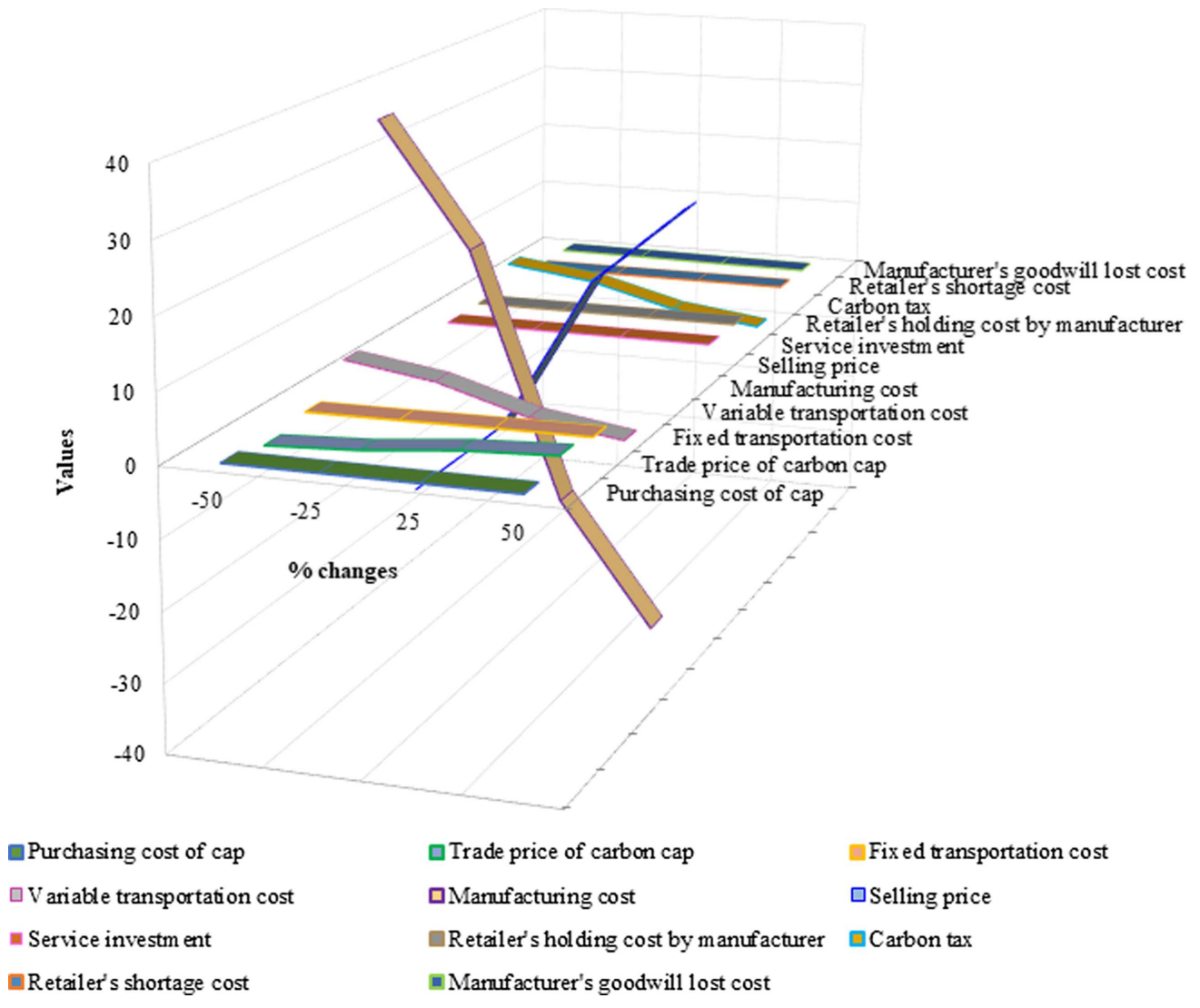

Figure 2. Sensitivity analysis of the key parameters.

cap trading price increases $+50 \%$, the profit increases $1.32 \%$. But, the cap trading price is more sensitive rather than the cap purchasing cost.

- Other lesser sensitive parameters are holding cost, goodwill lost cost of manufacturer, shortage cost of the retailer, the service investment, and customer satisfaction. Customer satisfaction and service investment have a similar types of changes and the impact of customer satisfaction is more than the service investment.

\section{MANAGERIAL IMPLICATIONS}

The results of the numerical experiments and case study imply that the non-coordination policy earns more profit than the coordination policy. This is a nice gesture to prevent unreliability within the SCM. The unreliability can be removed from the system by the decentralized system rather than the centralized system. The non-coordination policy of this study supports the decentralized secure system of blockchain to deal with the unreliability. Once the retailer passes any information towards upstream, it cannot be undone. Even if the retailer wants to change the data, the previous data still will be in the system and it cannot be erased from the system. Now, all retailers are separate body and they are not interconnected. Hence, there is no possibility of manipulation by each other. More importantly, once the data is saved in the system, it can not be undone by any means. Hence, information is secured in each block and it generates more profit for the unreliable supply chain. Industry can adapt this formula for this kind of unpleasant situation. 
TABLE 5. Sensitivity analysis of key parameters with respect to the expected total profit.

\begin{tabular}{|c|c|c|c|c|c|}
\hline Parameters & $\begin{array}{c}\text { Percentage changes } \\
\text { (in \%) }\end{array}$ & $\begin{array}{l}\text { Changes in total } \\
\text { profit }\end{array}$ & Parameters & $\begin{array}{c}\text { Percentage changes } \\
\text { (in \%) }\end{array}$ & $\begin{array}{l}\text { Changes in total } \\
\text { profit }\end{array}$ \\
\hline Manufacturing cost & $\begin{array}{l}-50 \\
-25 \\
+25 \\
+50\end{array}$ & $\begin{array}{l}+36.29 \\
+18.12 \\
-18.04 \\
-35.97\end{array}$ & Selling price & $\begin{array}{l}-50 \\
-25 \\
+25 \\
+50\end{array}$ & $\begin{array}{l}-23.05 \\
-11.65 \\
+11.68 \\
+23.37\end{array}$ \\
\hline Cap purchasing cost & $\begin{array}{l}-50 \\
-25 \\
+25 \\
+50\end{array}$ & $\begin{array}{l}-0.03 \\
-0.01 \\
+0.01 \\
+0.02\end{array}$ & Shortage cost & $\begin{array}{l}-50 \\
-25 \\
+25 \\
+50\end{array}$ & $\begin{array}{l}+0.014 \\
+0.007 \\
-0.007 \\
-0.014\end{array}$ \\
\hline $\begin{array}{l}\text { Trade price of } \\
\text { carbon limit }\end{array}$ & $\begin{array}{l}-50 \\
-25 \\
+25 \\
+50\end{array}$ & $\begin{array}{l}-1.32 \\
-0.66 \\
+0.66 \\
+1.32\end{array}$ & Carbon tax & $\begin{array}{l}-50 \\
-25 \\
+25 \\
+50\end{array}$ & $\begin{array}{l}+3.53 \\
+1.76 \\
-1.76 \\
-3.53\end{array}$ \\
\hline $\begin{array}{l}\text { Fixed Transportation } \\
\text { cost }\end{array}$ & $\begin{array}{l}-50 \\
-25 \\
+25 \\
+50\end{array}$ & $\begin{array}{l}-0.19 \\
-0.09 \\
+0.09 \\
+0.17\end{array}$ & Holding cost & $\begin{array}{l}-50 \\
-25 \\
+25 \\
+50\end{array}$ & $\begin{array}{l}+0.009 \\
+0.005 \\
-0.005 \\
-0.005\end{array}$ \\
\hline $\begin{array}{l}\text { Variable Transportation } \\
\text { cost }\end{array}$ & $\begin{array}{l}-50 \\
-25 \\
+25 \\
+50\end{array}$ & $\begin{array}{l}+3.97 \\
+1.96 \\
-1.96 \\
-3.97\end{array}$ & Service investment & $\begin{array}{l}-50 \\
-25 \\
+25 \\
+50\end{array}$ & $\begin{array}{l}+0.00007 \\
+0.00003 \\
-0.00002 \\
-0.00004\end{array}$ \\
\hline Goodwill lost cost & $\begin{array}{l}-50 \\
-25 \\
+25 \\
+50\end{array}$ & $\begin{array}{l}+0.17 \\
+0.08 \\
-0.08 \\
-0.16\end{array}$ & Customer satisfaction & $\begin{array}{l}-50 \\
-25 \\
+25 \\
+50\end{array}$ & $\begin{array}{l}+0.00009 \\
+0.00004 \\
-0.00003 \\
-0.00006\end{array}$ \\
\hline
\end{tabular}

Besides, the revenue sharing policy for the coordination case helps retailers to be tied in the SCM cooperation. As results show that the non-coordination policy has more profit than the coordination policy. Thus, when the system does business via coordination policy, retailers may not cooperate with the manufacturer. Because the coordination policy has less profit with more security. To attract retailers for the coordination policy, the revenue sharing policy is beneficial. Even, the shared profit with retailers in the coordination policy is more than the non-coordination policy. This implies that retailers will always choose to stay with the manufacturer in either way. This makes the system more reliable for coordination policy. Thus, the manufacturer can choose the best policy of business based on the situation for a long-term business relationship.

\section{Conclusions And FUture WORKS}

This study discussed an unreliable issue and its perspectives within an SCM. Unreliable multiple retailers created information asymmetry in the system and the manufacturer tried to solve this unpleasant circumstance to save profit. Results proved that the manufacturer succeeds to save profit and SCM collaboration in either way. For non-coordination case provided more profit by securing the information. These features of blockchain technology prevented the propagation of information asymmetry throughout the SCM. The manufacturer saved the coordination policy strategically by using revenue sharing with retailers. However, if retailers did not agree to the non-cooperation policy by any means, the coordination policy saved the SCM. The revenue-sharing strategy of the coordination policy of the SCM shared profit with retailers. This kept retailers stuck with the VMI policy instead of moving towards the traditional policy. Thus, the VMI policy of the manufacturer to deal with the unreliability was appropriate for both cases of coordination and non-coordination. Overall, the non-coordination policy is the better match for dealing with the unreliability issue in terms of information 
asymmetry. This study can be extended by using robust optimization. The mathematical model can be solved by using the game strategy for the non-coordination case. The advertisement policy is one of the game-changer for any business. The advertising has a great influence over the local customers for any specific kind of products. Thus, this study can be extended by using multi-product different advertisement policies.

Acknowledgements. This work was supported (in part) by the Yonsei University Research Fund (Post Doc. Researcher Supporting Program) of 2020 (project no.: 2020-12-0136). The work is supported by the National Research Foundation of Korea (NRF) grant, funded by the Korea Government (MSIT) (NRF-2020R1F1A1064460).

\section{REFERENCES}

[1] M.A.M. Abdel-Aal and S.Z. Selim, Robust optimization for selective newsvendor problem with uncertain demand. Comput. Indus. Eng. 135 (2019) 838-854.

[2] T.K. Agarwal, V. Kumar, R. Pal, L. Wang and Y. Chen, Blockchain-based framework for supply chain traceability: A case example of textile and clothing industry. Comp. Indust. Eng. 154 (2021) 107130.

[3] N.N. Ahamed and P. Karthikeyan, A reinforcement learning integrated in heuristic search method for self-driving vehicle using blockchain in supply chain management. Int. J. Intell. Net. 1 (2020) 92-101.

[4] Q. Bai and M. Chen, The distributionally robust newsvendor problem with dual sourcing under carbon tax and cap-and-trade regulations. Comput. Indust. Eng. 98 (2016) 260-274.

[5] E. Bazan, M.Y. Jaber, S. Zanoni and L.E. Zavanella, Vendor managed inventory (VMI) with consignment stock (CS) agreement for a two-level supply chain with an imperfect production process with/without restoration interruptions. Int. J. Prod. Econ. 157 (2014) 289-301.

[6] Y. Fan, M. Wang and L. Zhao, Production-inventory and emission reduction investment decision under carbon cap-and-trade policy. RAIRO: OR $\mathbf{5 2}$ (2018) 1043-1067.

[7] G. Gallego and I. Moon, The distribution free newsboy problem: Review and extensions. J. Oper. Res. Soc. 44 (1993) 825-834.

[8] S.K. Ghosh, M.R. Seikh and M. Chakraborty, Analyzing a stochastic dual-channel supply chain under consumers' low carbon preferences and cap-and-trade regulation. Comp. Indus. Eng. 149 (2020) 106765.

[9] R. Guchhait, M. Sarkar, B. Sarkar and S. Pareek, Single-vendor multi-buyer game theoretic model under multi-factor dependent demand. Int. J. Inv. Res. 4 (2017) 303-332.

[10] R. Guchhait, S. Pareek and B. Sarkar, Application of distribution-free approach in integrated and dual-channel supply chain under buyback contract. Handbook of Research on Promoting Business Process Improvement Through Inventory Control Techniques, edited by Nita H. Shah and Mandeep Mittal, IGI Global, USA, (2018) 388-426.

[11] R. Guchhait, S. Pareek and B. Sarkar, How does a radio frequency identification optimize the profit in an unreliable supply chain management? Mathematics 7 (2019) 1-19.

[12] J. Heydari and M. Ghasemi, A revenue sharing contract for reverse supply chain coordination under stochastic quality of returned products and uncertain remanufacturing capacity. J. Clean. Prod. 197 (2018) 607-615.

[13] J. Ji, Z. Zhang and L. Yang, Comparisons of initial carbon allowance allocation rules in an O2O retail supply chain with the cap-and-trade regulation. Int. J. Prod. Econ. 187 (2017) 68-84.

[14] Y. Karimian, A. Mirzazadeh, S.H. Pasandideh and M. Namakshenas, A geometric programming approach for a vendor managed inventory of a multiretailer multi-item EPQ model. RAIRO: OR 54 (2020) 1401-1418.

[15] C. Kegui, W. Xinyu, H. Min and R. Liang, Monitoring strategies of enterprise's emission reduction with asymmetric information. RAIRO: OR 55 (2021) S2455-S2470.

[16] M. Lashgari, A.A. Taleizadeh and A. Ahmadi, Partial up-stream advanced payment and partial down-stream delayed payment in a three-level supply chain. Ann. Oper. Res. 238 (2016) 329-354.

[17] H. Li, M. Shang, X. Qin, R. Li and Y. Tan, Optimal cap setting and pricing in supply chains under vertical-horizontal cooperation and cap-and-trade regulation. RAIRO: OR 55 (2021) S2487-S2508.

[18] I. Moon, E. Sin and B. Sarkar, Min-max distribution free continuous review model with a service level constraint and variable lead time. Int. J. Manag. Sci. Eng. Manag. 14 (2019) 113-123.

[19] S.K. Mukhopadhyay, D.Q. Yao and X.Y. Yue, Information sharing of value-adding retailer in a mixed channel hi-tech supply chain. J. Busi. Res. 61 (2008) 950-958.

[20] S.K. Mukhopadhyay, X. Zhu and X. Yue, Optimal contract design for mixed channels under information asymmetry. Prod. Oper. Manag. 17 (2009) 641-650.

[21] S.K. Mukhopadhyay, X. Yue and X. Zhu, A Stackelberg model of pricing of complementary goods under information asymmetry. Int. J. Prod. Econ. 134 (2011) 424-433.

[22] M. Noori-Daryan, A.A. Taleizadeh and K. Govindan, Joint replenishment and pricing decisions with different freight modes considerations for a supply chain under a composite incentive contract. J. Oper. Res. Soc. 69 (2017) 876-894.

[23] E. Rezaei, M.M. Paydar and A.S. Safaei, Customer relationship management and new product development in designing a robust supply chain. RAIRO: OR 54 (2020) 369-391. 
[24] M.R. Rezayat, S. Yaghoubi and A. Fander, A hierarchical revenue-sharing contract in electronic waste closed-loop supply chain. Waste. Manag. 115 (2020) 121-135.

[25] S.J. Sadjadi and A. Alirezaee, Impact of pricing structure on supply chain coordination with cooperative advertising. RAIRO: OR 54 (2020) 1613-1629.

[26] I.G. Sahebi, B. Masoomi and S. Ghorbani, Expert oriented approach for analyzing the blockchain adoption barriers in humanitarian supply chain. Tech. Soc. 63 (2020) 101427.

[27] I. Sangal, B.K. Shaw, B. Sarkar and R. Guchhait, A joint inventory model with reliability, carbon emission, and inspection errors in a defective production system. Yugos. J. Oper. Res. 30 (2020) 381-398.

[28] S.K. Sardar, B. Sarkar and B. Kim, Integrating machine learning, radio frequency identification, and consignment policy for reducing unreliability in smart supply chain management. Processes 9 (2021) 247.

[29] B. Sarkar, C. Zhang, A. Majumder, M. Sarkar and W.Y. Seo, Distribution free newsvendor model with consignment policy and retailer's royalty reduction. Int. J. Prod. Res. 56 (2018) 5025-5044.

[30] B. Sarkar, S.P. Mondal, S. Hur, A. Ahmadian, S. Salahshour, R. Guchhait and M.W. Iqbal, An optimization technique for national income determination model with stability analysis of differential equation in discrete and continuous process under the uncertain environment. RAIRO: OR 53 (2019) 1649-1674.

[31] H. Scarf, A min-max solution of an inventory problem. Studies in the Mathematical Theory of Inventory and Production, edited by K.J. Arrow, S. Karlin and H.E. Scarf. Stanford University Press (1958).

[32] F.T. Sunmola, Context-aware blockchain-based sustainable supply chain visibility management. Proc. Comp. Sci. 180 (2021) $887-892$.

[33] A.A. Taleizadeh, N. Alizadeh-Basban and S.T.A. Niaki, A closed-loop supply chain considering carbon reduction, quality improvement effort, and return policy under two remanufacturing scenarios. J. Clean. Prod. 232 (2019) 1230-1250.

[34] A.A. Taleizadeh, F. Haghighi and S.T.A. Niaki, Modeling and solving a sustainable closed loop supply chain problem with pricing decisions and discounts on returned products. J. Clean. Prod. 207 (2019) 163-181.

[35] A.A. Taleizadeh, I. Shokr, I. Konstantaras and M. VafaeiNejad, Stock replenishment policies for a vendor-managed inventory in a retailing system. J. Ret. Cons. Ser. 55 (2020) 102137.

[36] M. Ullah, I. Asghar, M. Zahid, M. Omair, A. AlArjani and B. Sarkar, Ramification of remanufacturing in a sustainable three-echelon closed-loop supply chain management for returnable products. J. Clean. Prod. 290 (2021) 125609.

[37] M.K.C.S. Wijewickrama, N. Chileshe, R. Rameezdeen and J.J. Ochoa, Information sharing in reverse logistics supply chain of demolition waste: A systematic literature review. J. Clean. Prod. 280 (2021) 124359.

[38] A. Yang, Y. Li, C. Liu, J. Li, Y. Zhang and J. Wang, Research on logistics supply chain of iron and steel enterprises based on block chain technology. Futur. Gener. Comp. Syst. 10 (2019) 635-645.

[39] B. Yu, J. Wang, X. Lu and H. Yang, Collaboration in a low-carbon supply chain with reference emission and cost learning effects: Cost sharing versus revenue sharing strategies. J. Clean. Prod. 250 (2020) 119460.

[40] W. Zhang and H. Chu, Coordination for pull and push contracts in decentralized system with uncertain supply. RAIRO: OR 55 (2021) S647-S672.

\section{Subscribe to Open (S20) A fair and sustainable open access model}

This journal is currently published in open access under a Subscribe-to-Open model (S2O). S2O is a transformative model that aims to move subscription journals to open access. Open access is the free, immediate, online availability of research articles combined with the rights to use these articles fully in the digital environment. We are thankful to our subscribers and sponsors for making it possible to publish this journal in open access, free of charge for authors.

\section{Please help to maintain this journal in open access!}

Check that your library subscribes to the journal, or make a personal donation to the $\mathrm{S} 2 \mathrm{O}$ programme, by contacting subscribers@edpsciences.org

More information, including a list of sponsors and a financial transparency report, available at: https://www. edpsciences.org/en/maths-s2o-programme 